\title{
Acute Effects of Inhaled Isoproterenol on the Mechanical Characteristics of the Lungs in Normal Man
}

\author{
E. R. McFadden, Jr., Jan Newton-Howes, and N. B. Prme \\ From the Department of Medicine, Royal Postgraduate Medical School, \\ Hammersmith Hospital, London, W. 12., England
}

\begin{abstract}
A B S T RAC T We investigated the effects of isoproterenol on the pulmonary mechanics of eight healthy male subjects. We measured the flow-volume, pressurevolume, resistance-volume, and pressure-flow relationships of the lungs of our subjects in addition to the forced expiratory volume $\left(\mathrm{FEV}_{1}\right)$. The results of this study confirm earlier observations that isoproterenol produces a considerable decrease in airway resistance but only small changes in maximum expiratory flow. Measurements of static pressure-volume curves showed that isoproterenol caused a temporary decrease in the elastic recoil pressure of the lungs. In five men there were mean falls in recoil pressure of $4.1 \mathrm{~cm} \mathrm{H} \mathrm{H}_{2} \mathrm{O}$ at $85 \%$ total lung capacity (TLC), $2.6 \mathrm{~cm} \mathrm{H}_{2} \mathrm{O}$ at $75 \%$ TLC, and $1.5 \mathrm{~cm} \mathrm{H}_{2} \mathrm{O}$ at $50 \%$ TLC. We postulate that the reason for the relatively small increments in maximum expiratory flow after isoproterenol is primarily that the effects of airway dilatation are in large part negated by the reduction in lung recoil pressure, which results in a fall in the maximum effective driving force for expiratory air flow, and secondly that there is an increase in the compliance of the flow-limiting airways. These studies emphasize that tests of maximum flow and of airway resistance should not be regarded as invariably interchangeable in the assessment of airway reactions or mild disease of the airways.
\end{abstract}

\section{INTRODUCTION}

In the past $15 \mathrm{yr}$ a large number of techniques have been developed for the assessment of the severity of generalized airways obstruction. Of these, the most widely used are measurements of airways resistance,

This work was performed during Dr. McFadden's tenure of a British-American Research Fellowship supported by the American Heart Association and British Heart Foundation. Dr. McFadden's present address is Department of Medicine, William Beaumont General Hospital, El Paso, Tex.

Received for publication 18 September 1969 and in revised form 19 November 1969. made while the subject maintains a tidal breathing pattern, and various techniques that assess the changes in flow or volume that occur during the course of a single forced expiration, the most familiar of these being the 1-sec forced expiratory volume $\left(F E V_{1}\right)$. In general these two tests have been regarded as being interchangeable in the evaluation of established obstruction of the airways. On theoretical grounds, however, it is possible to visualize situations where changes in maximum expiratory flow occur without there being a change in airways resistance measured in the body plethysmograph, or conversely, where changes in resistance do not result in a change in maximum expiratory flow. A striking example of this type of discrepancy has been observed in normal subjects after the inhalation of isoproterenol, in whom it has been shown that, despite a considerable fall in airway resistance and rise in anatomical dead space $(1-4)$, there is very little change in the $\mathrm{FEV}_{1}$ (4). In the present study we have examined in detail the alterations in pulmonary mechanics that occur in normal subjects after isoproterenol in an effort to determine the causes of this particular pattern of change. We believe that this analysis provides information of more general application on the interrelations between tests of pulmonary function made during quiet breathing and during the course of a forced expiration.

\section{METHODS}

We studied the pulmonary function of eight healthy male subjects whose ages ranged from 26 to $37 \mathrm{yr}$. Our investigations included measurements of airway resistance ( $\mathrm{Ra})$, total lung capacity and its subdivisions, 1-sec forced expiratory volumes, maximum mid-expiratory flow rates, and maximum expiratory flow-volume curves. We explored the relationship between airway conductance $(\mathrm{Ga})$ (the reciprocal of resistance) and lung volume (TGV) over the entire vital capacity in triplicate, by using a constant volume body plethysmograph $(5,6)$. Total lung capacity (TLC) and residual volume (RV) were obtained by the methods of Dubois, Botelho, and Comroe (5). 1-sec forced expira- 
tory volume $\left(F E V_{1}\right)$ and maximum expiratory flow-volume curves (MEFV) were recorded simultaneously by having the subjects expire forcefully through a heated pneumotachograph (7) whose output was electrically integrated. Flow and volume were exhibited on the ordinate and abscissa, respectively, of an xy storage oscilloscope (Techtronix model No. 564). The volume signal was also monitored on a time base, high speed, paper recorder (Mingograf No. 1240) to give the $\mathrm{FEV}_{1}$. Maximum mid-expiratory flow (MMF) was calculated from the forced expiratory volume tracings (8). After completion of these studies, each subject inhaled aerosols of a $1 \%$ solution of isoproterenol from a Wright nebulizer for $5 \mathrm{~min}$. $10 \mathrm{~min}$ later we repeated all of the investigations outlined above.

In a second series of experiments, we undertook a more extensive evaluation of pulmonary mechanics, before and after. isoproterenol, in five of our subjects. After each had inhaled to TLC several times (9), we determined the expiratory static pressure-volume relationships of their lungs by measuring the pressure difference between an esophageal balloon and mouth (10), and lung volumes with a constant pressure plethysmograph (11). Balloon volume and position were checked before and after each measurement. The resultant lung elastic recoil curves represent the mean of at least three determinations. Isovolume pressure-flow curves (IVPF) were obtained by having the subjects perform a series of expirations from total lung capacity to residual volume with varying force, beginning with slow sighing respiration and proceeding up to maximum efforts (12-14). Airflow $\left(V_{w}\right)$, transpulmonary pressure, and lung volume from the plethysmograph were displayed on an $x y$ storage scope. Flow rates and pressure were both recorded on the ordinate by the use of a split beam channel while volumes were recorded on the abscissa. Dynamic transpulmonary pressure was added algebraically to the static recoil pressure ( $P_{\text {st }}[1]$ ) at the same lung volume to give alveolar pressure $\left(P_{a 1 v}\right)$ which was plotted against the simultaneously occurring airflow. Lines of best fit, as determined by inspection, were drawn through the data points.

The isovolume pressure-flow curves were analyzed using the equal pressure point concept of Mead, Turner, Macklem, and Little (15). This allowed us to partition total pulmonary resistance into two segments, arranged in series upstream and downstream from the equal pressure point as follows:

$$
\begin{aligned}
\dot{\mathrm{V}} \mathrm{E}_{\max }= & \text { maximum expiratory airflow at any lung volume, } \\
& \text { corresponding to the plateau value on an IVPF } \\
& \text { curve. } \\
\mathrm{P}_{\mathrm{alv}}= & \mathrm{P}_{\mathrm{st}}(1)+\mathrm{P}_{\mathrm{pl}} \\
\mathrm{P}_{\mathrm{alv}}{ }^{1}= & \text { the lowest value of alveolar pressure associated } \\
& \text { with maximum expiratory flow. } \\
\mathrm{R}_{\mathrm{T}}= & \text { total pulmonary resistance computed at } \mathrm{P}_{\mathrm{alv}}{ }^{1} . \\
\mathrm{Rus}= & \text { Resistance of those airways running from the } \\
& \text { alveolus to the equal pressure point with } \mathrm{P}_{\mathrm{st}}(1) \\
& \text { as the driving pressure (upstream segment). } \\
\mathrm{Rd}= & \text { Resistance of those airways running from the equal } \\
& \text { pressure point to the mouth with } \mathrm{P}_{\mathrm{alv}}-\mathrm{P}_{\mathrm{st}}(1) \text { as } \\
& \text { the driving pressure (downstream segment). }
\end{aligned}
$$

Since $R_{T}$ equals the sum of the resistances of the upstream and downstream segments

$$
R_{T}=R u s+R d=\frac{P_{\mathbf{a l v}^{1}}}{\dot{V}_{E_{\max }}}
$$

\begin{tabular}{|c|c|c|c|c|c|c|c|c|c|c|c|c|c|c|c|c|c|}
\hline \multirow[b]{2}{*}{ Subject } & \multirow[b]{2}{*}{ Age } & \multicolumn{2}{|c|}{ MMF } & \multicolumn{2}{|c|}{$\mathrm{FEV}_{1}$} & \multicolumn{2}{|c|}{$\mathbf{R a}$} & \multicolumn{2}{|c|}{ TGV } & \multicolumn{2}{|c|}{$\mathrm{SGa}$} & \multicolumn{2}{|c|}{ TLC } & \multicolumn{2}{|c|}{$\mathrm{VC}$} & \multicolumn{2}{|c|}{ RV } \\
\hline & & B & A & B & $\mathbf{A}$ & B & A & B & A & B & $\mathbf{A}$ & B & A & B & A & B & A \\
\hline & $y r$ & \multicolumn{2}{|c|}{ liter $/ \min$} & \multicolumn{2}{|c|}{ liler } & \multicolumn{2}{|c|}{$\begin{array}{c}\mathrm{Cm}_{\mathrm{H}} \mathrm{O}_{2} \mathrm{O} / \\
\text { liter } / \mathrm{sec}\end{array}$} & \multicolumn{2}{|c|}{ liter } & \multicolumn{2}{|c|}{$\begin{array}{c}\text { litcr } / \mathrm{sec} / \mathrm{cm} \\
\mathrm{H}_{2} \mathrm{O} / \text { liter }\end{array}$} & \multicolumn{2}{|c|}{ liter } & \multicolumn{2}{|c|}{ liter } & \multicolumn{2}{|c|}{ liter } \\
\hline D. D. & 36 & 173 & 252 & 4.01 & 4.31 & 1.67 & 0.95 & 4.37 & 4.19 & 0.14 & 0.25 & 7.65 & 7.80 & 5.90 & 6.10 & 1.72 & 1.74 \\
\hline G. F. & 35 & 361 & 463 & 4.93 & 5.24 & 0.73 & 0.55 & 3.80 & 3.65 & 0.36 & 0.49 & 8.06 & 8.07 & 6.07 & 6.18 & 1.99 & 1.88 \\
\hline N. P. & 37 & 314 & 352 & 4.57 & 4.64 & 0.95 & 0.78 & 3.60 & 3.68 & 0.29 & 0.31 & 7.13 & 7.39 & 5.40 & 5.40 & 1.73 & 1.94 \\
\hline A. R. & 27 & 329 & 361 & 4.74 & 4.81 & 0.93 & 0.83 & 3.32 & 3.21 & 0.35 & 0.38 & 7.15 & 7.02 & 5.75 & 5.60 & 1.40 & 1.42 \\
\hline D. R. & 32 & 215 & 278 & 3.58 & 3.61 & 1.67 & 1.18 & 3.28 & 3.14 & 0.19 & 0.27 & 5.88 & 6.05 & 4.00 & 4.11 & 1.88 & 1.94 \\
\hline D. M. & 31 & 327 & 351 & 5.51 & 5.79 & 0.65 & 0.63 & 4.30 & 4.04 & 0.36 & 0.40 & 8.89 & 9.00 & 7.07 & 7.10 & 1.82 & 1.90 \\
\hline S. & 26 & 182 & 233 & 3.74 & 4.03 & 1.11 & 0.95 & 2.96 & 2.89 & 0.28 & 0.36 & 6.43 & 6.40 & 5.00 & 4.92 & 1.43 & 1.48 \\
\hline G. J. & 29 & 253 & 302 & 3.85 & 4.01 & 1.15 & 0.91 & 3.32 & 3.28 & 0.23 & 0.35 & 5.71 & 5.79 & 4.83 & 4.79 & 0.89 & 1.00 \\
\hline Mean & & 296 & 324 & 4.37 & 4.56 & 1.11 & 0.85 & 3.62 & 3.57 & 0.28 & 0.35 & 7.11 & 7.19 & 5.51 & 5.52 & 1.61 & 1.66 \\
\hline$\pm \mathrm{SD}$ & & 73 & 74 & 0.68 & 0.72 & 0.39 & 0.20 & 0.51 & 0.46 & 0.08 & 0.08 & 1.09 & 1.10 & 0.93 & 0.96 & 0.36 & 0.34 \\
\hline$P$ Value & & \multicolumn{2}{|c|}{0.002} & \multicolumn{2}{|c|}{0.003} & \multicolumn{2}{|c|}{0.02} & \multicolumn{2}{|c|}{0.10} & \multicolumn{2}{|c|}{0.001} & \multicolumn{2}{|c|}{0.12} & \multicolumn{2}{|c|}{0.66} & \multicolumn{2}{|c|}{0.11} \\
\hline
\end{tabular}

By definition,

$$
\text { Rus }=\frac{P_{s t}(1)}{\dot{V}_{E_{\max }}}
$$

therefore,

$$
\operatorname{Rd}=\frac{P_{\mathrm{alv}}-P_{\mathrm{st}}(1)}{\dot{\mathrm{V}} \mathrm{E}_{\max }}
$$

furthermore, by rearrangement,

$$
\mathrm{P}_{\mathrm{alv}}{ }^{1}=\left(\dot{\mathrm{V}} \mathrm{E}_{\max } \cdot \mathrm{Rus}\right)+\left(\dot{\mathrm{V}} \mathrm{E}_{\max } \cdot \mathrm{Rd}\right)
$$

TABLE I

Comparison of Spirometric and Plethysmographic Data before and after Isoproterenol

$\mathrm{MMF}=$ maximum midexpiratory flow rates; $\mathrm{FEV}_{1}=1-\mathrm{sec}$ forced expiratory volume; Ra = airway resistance; TGV $=$ thoracic gas volume measured at functional residual capacity; $\mathrm{SGa}=$ specific conductance; TLC $=$ total lung capacity; $\mathrm{VC}=$ vital capacity $; \mathrm{RV}=$ residual volume $; \mathrm{B}=$ before isoproterenol; $\mathrm{A}=$ af ter isoproterenol ; all lung volumes are expressed in BTPS. 

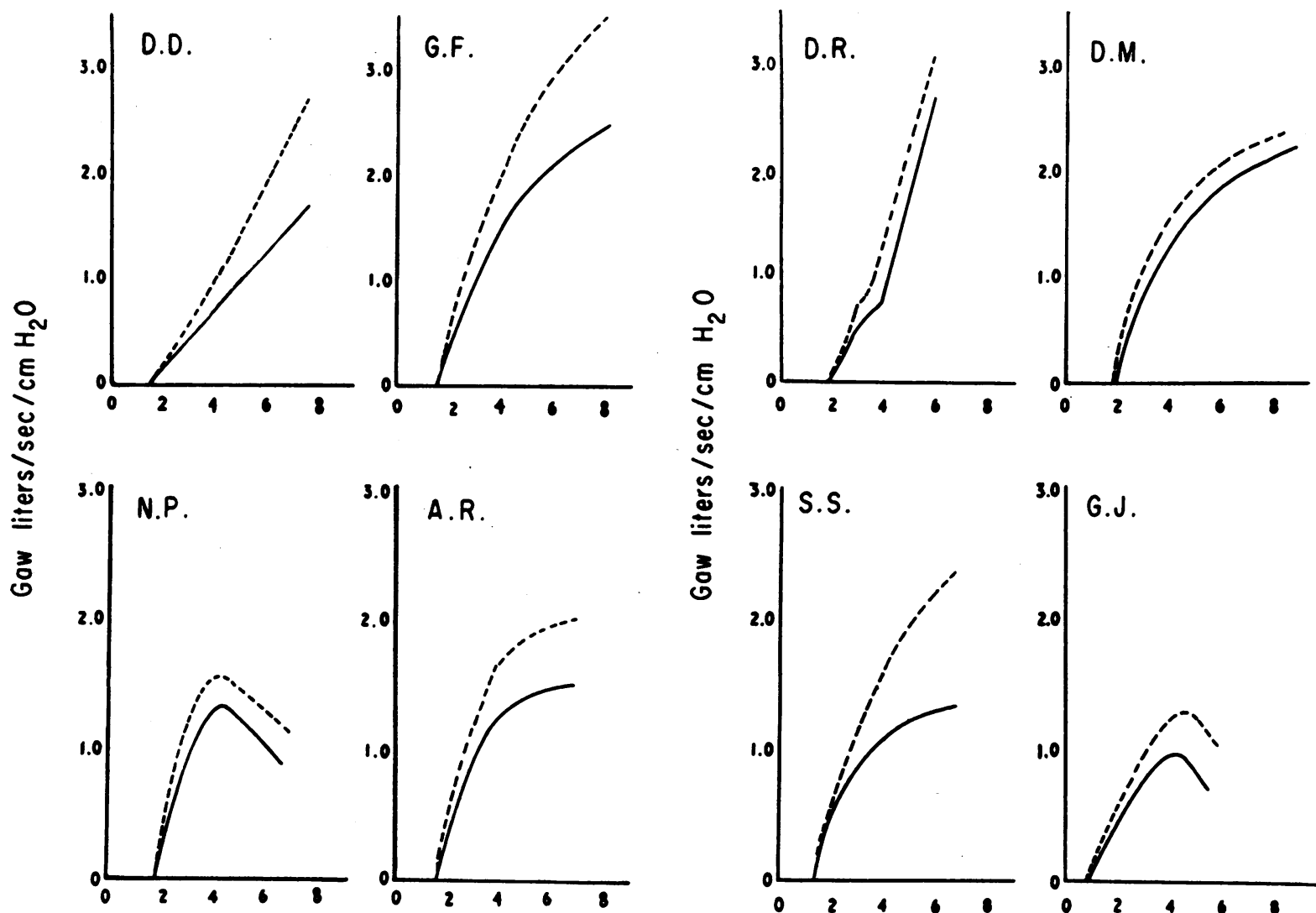

A

Volume Liters

B

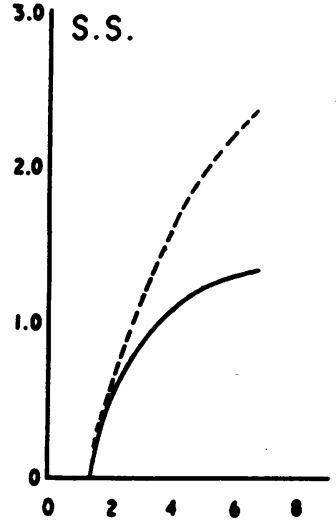

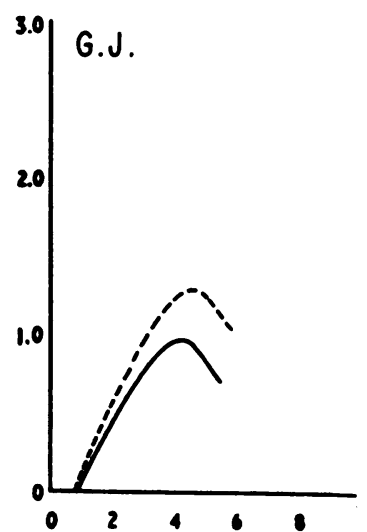

Volume Liters

FIGURE 1 The effect of isoproterenol on the conductance-lung volume relationship of each subject. Solid lines represent control observations, broken lines indicate postisoproterenol values.

Substituting,

$$
\begin{aligned}
\mathrm{P}_{\mathrm{alv}}{ }^{1} & =\mathrm{P}_{\mathrm{st}}(1)+\left(\frac{\mathrm{P}_{\mathrm{st}}(1)}{\mathrm{Rus}} \cdot \mathrm{Rd}\right) \\
& =\mathrm{P}_{\mathrm{st}}(1)\left(1+\frac{\mathrm{Rd}}{\mathrm{Rus}}\right)
\end{aligned}
$$

We also obtained postero-anterior chest radiographs at full lung inflation in each subject before and $10 \mathrm{~min}$ after isoproterenol inhalation.

\section{RESULTS}

The effect of isoproterenol on the conventional measures of pulmonary mechanics and lung volumes is shown in Table I. As expected there was a significant fall (mean $26 \%$ ) in airway resistance and an increase in specific conductance (i.e. conductance:thoracic gas volume ratio) after isoproterenol. This increase in airway dimensions was confirmed by radiographs which showed that the transverse diameter of the trachea immediately above the carina increased by $5.6 \%$ following isoproterenol (from a mean of $3.4 \pm 0.2$ to $3.6 \pm 0.2 \mathrm{~cm}$;
$P=0.003)$. Despite these improvements in airway size, the FEV 1 only increased $4.4 \%$ over its previous value. The maximum mid-expiratory flow rate improved $9.4 \%$. There was no change in total lung capacity or its subdivisions.

A comparison of $\mathrm{FEV}_{1}$ with specific conductance may have limited value because the measurements are not made at comparable lung volumes. If isoproterenol exerted its greatest effect low in the vital capacity, airway resistance and maximum mid-expiratory flow rates would be expected to change since they are measured close to FRC. However, the FEV 1 might be unaltered because it is dominated by the airflow that can be achieved high in the vital capacity. Furthermore, the $F_{1}$ is such a large proportion of the vital capacity in normal subjects that there is little opportunity for it to increase further when there is no change in the vital capacity. We therefore evaluated the relationships of conductance and maximum expiratory flow to lung volume. Fig. 1 demonstrates that isoproterenol caused 


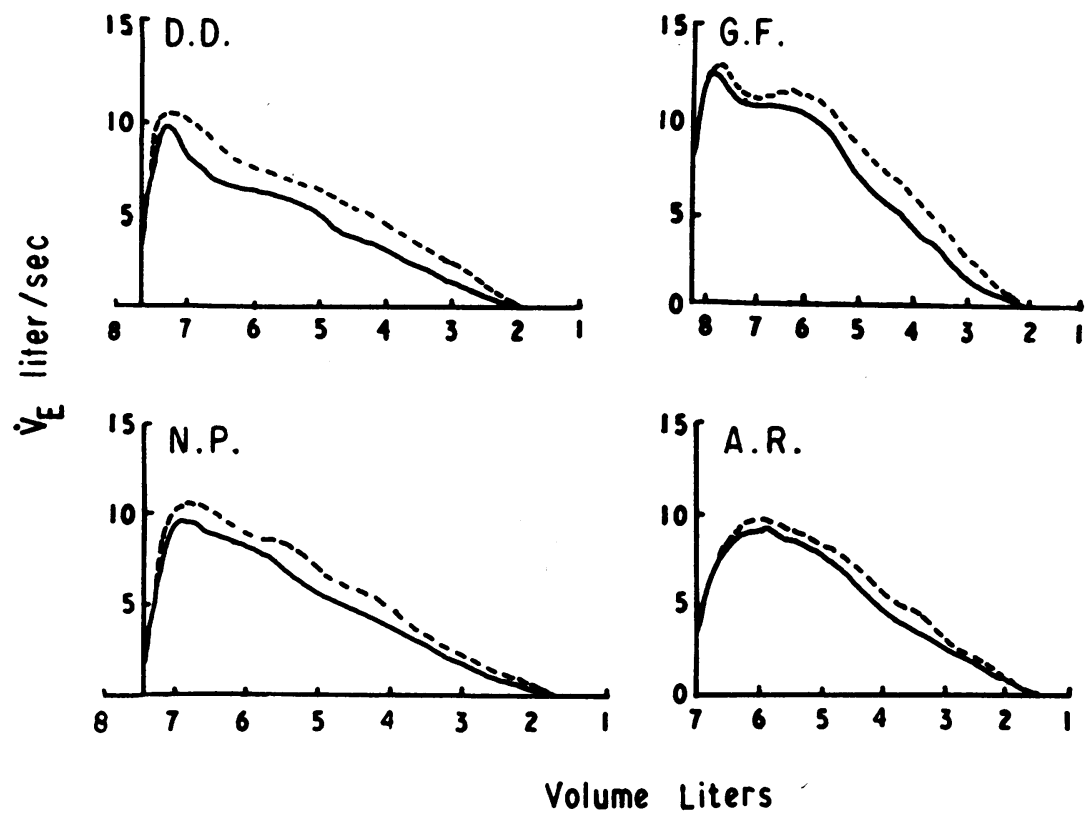

FIGURE 2 Maximum expiratory flow-volume curves of four subjects. Solid lines indicate control values; broken lines represent the observations made after isoproterenol.

an increase in conductance at all lung volumes, in each individual, with the greatest improvement occurring above $50 \%$ of the vital capacity. Comparison of maximum expiratory flow-volume curves before and after isoproterenol (Figs. 2 and 3 ) showed that, although maximum airflow increased throughout expiration, the improvement did not parallel the changes in resting conductance. In fact, the greatest percentage change in flow rates occurred at lung volumes below $50 \%$ of the vital capacity. Fig 4 and Table II combine these observations by relating the MEFV curves to airway conductance. At volumes low in the vital capacity, the

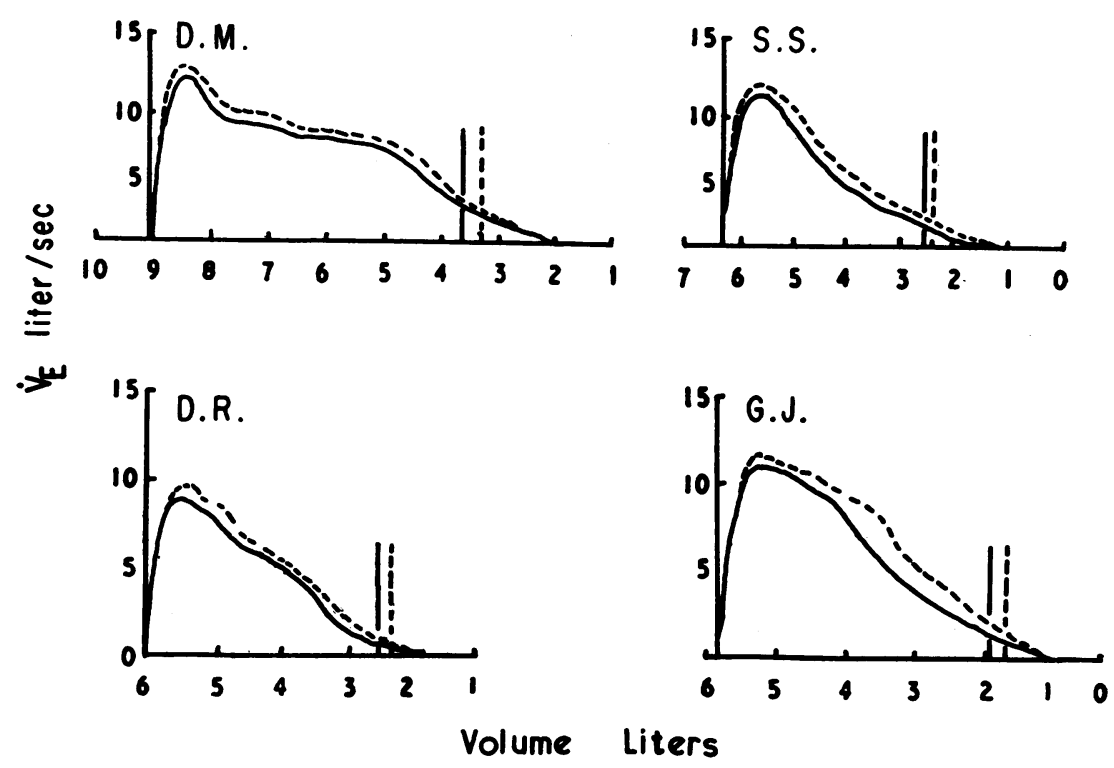

FIGURE 3 MEFV curves of four subjects. Solid lines indicate control values; broken lines represent the observations made after isoproterenol. The vertical lines indicate the values for the $\mathrm{FEV}_{1}$ in these subjects. 


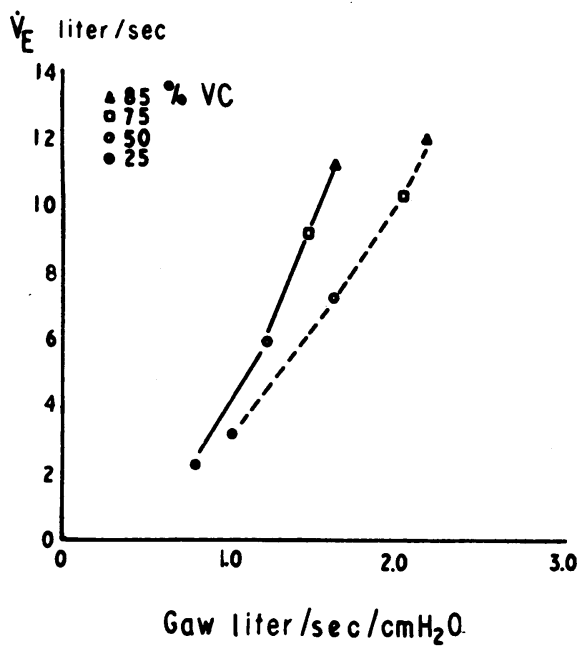

FIGURE 4 The relationship of maximum expiratory flow (from MEFV curves) to airway conductance at various lung volumes. Solid line indicates control study, while the broken line represents the effects of isoproterenol. Data points are mean values.

small change in conductance was associated with a disproportionately large increase in flow, whereas the reverse was found to be true at higher levels of lung inflation. This first group of studies shows, therefore, that the discrepancy suggested by the previous measurements of airways resistance, MMF and the $\mathrm{FEV}_{1}$, could not be attributed solely to these observations being made at different lung volumes. They further suggest that measurements of maximal flow made at low lung volumes might be more sensitive than the $\mathrm{FEV}_{1}$ in detecting small deviations from normal. They do not, however, give any clue as to why this should occur.

The relationship between conductance or resistance measured at low flow rates (by plethysmography) and the maximum expiratory flow at a particular lung volume can be visualized on an iso-volume pressure-flow curve (Fig. 5). It is evident from inspection of the normal curve that there could be a reduction in maximum flow without any change in the initial slope of the curve from its origin in two circumstances: first, if there was increased curvilinearity of the curve at higher. flow rates; and second, if the alveolar pressure at which maximum flow was first reached $\left(\mathrm{P}_{\mathbf{2} 1 \mathbf{v}^{1}}\right)$ was reduced. Therefore, we obtained IVPF curves in five of our subjects at several different lung volumes, before and after isoproterenol, in order to determine why maximum expiratory flow was so little increased at larger lung volumes in the first study.

All iso-volume pressure flow points in subject D.D. are presented in Fig. 6; those from the other subjects demonstrate the same phenomena. We observed flow plateaux at lung volumes up to $75 \%$ of the vital capacity. In contrast to Fry and Hyatt's results (14), we were unable to demonstrate a consistent flow decrease at pressures higher than those corresponding to the beginning of the flow plateau. Although it is difficult to define precise values of $\mathrm{P}_{\mathrm{a} 1 \mathrm{v}}{ }^{1}$ on any IVPF curve, nevertheless, it is apparent that this value tends to fall as lung volume

TABLE II

Comparison of Airway Conductance and Maximum Expiratory Flow Volume Curves at Various Lung Volumes

\begin{tabular}{|c|c|c|c|c|c|c|c|c|c|c|c|c|c|c|c|c|}
\hline \multirow[b]{4}{*}{ Subject } & \multicolumn{16}{|c|}{ Per cent vital capacity } \\
\hline & \multicolumn{4}{|c|}{$85 \%$} & \multicolumn{4}{|c|}{$75 \%$} & \multicolumn{4}{|c|}{$50 \%$} & \multicolumn{4}{|c|}{$25 \%$} \\
\hline & \multicolumn{2}{|c|}{$\mathrm{Ga}$} & \multicolumn{2}{|c|}{$\dot{\mathrm{V}}_{\mathbf{E}}$} & \multicolumn{2}{|c|}{$\mathrm{Ga}$} & \multicolumn{2}{|c|}{$\dot{\mathrm{V}}_{\mathbf{E}}$} & \multicolumn{2}{|c|}{ Ga } & \multicolumn{2}{|c|}{$\dot{\mathrm{V}}_{\mathbf{E}}$} & \multicolumn{2}{|c|}{$\mathrm{Ga}$} & \multicolumn{2}{|c|}{$\dot{\mathrm{V}}_{\mathbf{E}}$} \\
\hline & B & A & B & $\mathbf{A}$ & B & A & B & A & B & A & B & A & B & A & B & $\mathbf{A}$ \\
\hline & \multicolumn{2}{|c|}{$\begin{array}{l}\text { liter } / \mathrm{sec} \text { per } \\
\mathrm{cm} \mathrm{H}, \mathrm{O}\end{array}$} & \multicolumn{2}{|c|}{ liter/sec } & \multicolumn{2}{|c|}{$\begin{array}{l}\text { liter } / \mathrm{sec} \text { per } \\
\mathrm{Cm} \mathrm{H}_{2} \mathrm{O}\end{array}$} & \multicolumn{2}{|c|}{ liter $/ \mathrm{sec}$} & \multicolumn{2}{|c|}{$\begin{array}{l}\text { liler } / \mathrm{sec} \text { per } \\
\mathrm{cm} \mathrm{H}_{2} \mathrm{O}\end{array}$} & \multicolumn{2}{|c|}{ liter $/$ sec } & \multicolumn{2}{|c|}{$\begin{array}{l}\text { liter } / \mathrm{sec} \text { per } \\
\mathrm{cm} \mathrm{H}_{2} \mathrm{O}\end{array}$} & \multicolumn{2}{|c|}{ liter/sec } \\
\hline D. D. & 1.70 & 2.20 & 9.8 & 10.8 & 1.30 & 2.10 & 6.5 & 8.3 & 0.90 & 1.30 & 4.3 & 5.8 & 0.45 & 0.60 & 2.0 & 3.1 \\
\hline G. F. & 2.40 & 3.45 & 12.3 & 12.8 & 2.25 & 3.20 & 10.6 & 11.3 & 1.90 & 2.60 & 6.8 & 8.3 & 1.25 & 1.75 & 2.4 & 4.1 \\
\hline N. P. & 0.90 & 1.20 & 12.8 & 14.0 & 1.05 & 1.30 & 10.5 & 11.4 & 1.30 & 1.50 & 6.5 & 8.2 & 0.84 & 1.14 & 2.1 & 2.9 \\
\hline A. $\mathrm{R}$. & 1.50 & 1.94 & 12.8 & 13.4 & 1.45 & 1.94 & 11.7 & 12.7 & 1.32 & 1.84 & 7.3 & 8.0 & 0.86 & 1.08 & 2.7 & 3.3 \\
\hline D. R. & 2.25 & 2.75 & 8.8 & 9.3 & 1.75 & 2.20 & 7.3 & 8.2 & 0.75 & 1.30 & 4.8 & 5.8 & 0.50 & 1.75 & 1.7 & 2.0 \\
\hline D. M. & 2.25 & 2.65 & 12.5 & 12.8 & 2.05 & 2.20 & 9.2 & 9.8 & 1.75 & 1.90 & 7.9 & 8.8 & 1.18 & 1.40 & 3.3 & 4.4 \\
\hline S. S. & 1.30 & 2.30 & 10.8 & 11.7 & 1.22 & 2.00 & 8.8 & 10.5 & 1.06 & 1.52 & 4.2 & 5.0 & 0.76 & 0.92 & 1.5 & 2.1 \\
\hline G. J. & 0.80 & 1.10 & 11.0 & 11.3 & 0.92 & 1.20 & 10.0 & 10.4 & 0.84 & 1.10 & 5.2 & 7.5 & 0.50 & 0.60 & 2.0 & 2.6 \\
\hline Mean & 1.64 & 2.20 & 11.4 & 12.0 & 1.50 & 2.03 & 9.3 & 10.3 & 1.23 & 1.63 & 5.9 & 7.2 & 0.79 & 1.03 & 2.2 & 3.1 \\
\hline$\pm \mathrm{SD}$ & 0.62 & 0.79 & 1.5 & 1.5 & 0.48 & 0.61 & 1.8 & 1.5 & 0.42 & 0.48 & 1.4 & 1.5 & 0.31 & 0.40 & 0.6 & 0.9 \\
\hline$P$ Value & \multicolumn{2}{|c|}{0.001} & \multicolumn{2}{|c|}{0.0008} & \multicolumn{2}{|c|}{0.001} & \multicolumn{2}{|c|}{0.0008} & \multicolumn{2}{|c|}{0.0005} & \multicolumn{2}{|c|}{0.0003} & \multicolumn{2}{|c|}{0.001} & \multicolumn{2}{|c|}{0.001} \\
\hline
\end{tabular}

$\mathrm{Ga}=$ airway conductance; $\dot{\mathrm{V}}_{\mathbf{E}}=$ maximum expiratory flow rates; $\mathrm{B}=$ before isoproterenol; $\mathrm{A}=$ after isoproterenol. 


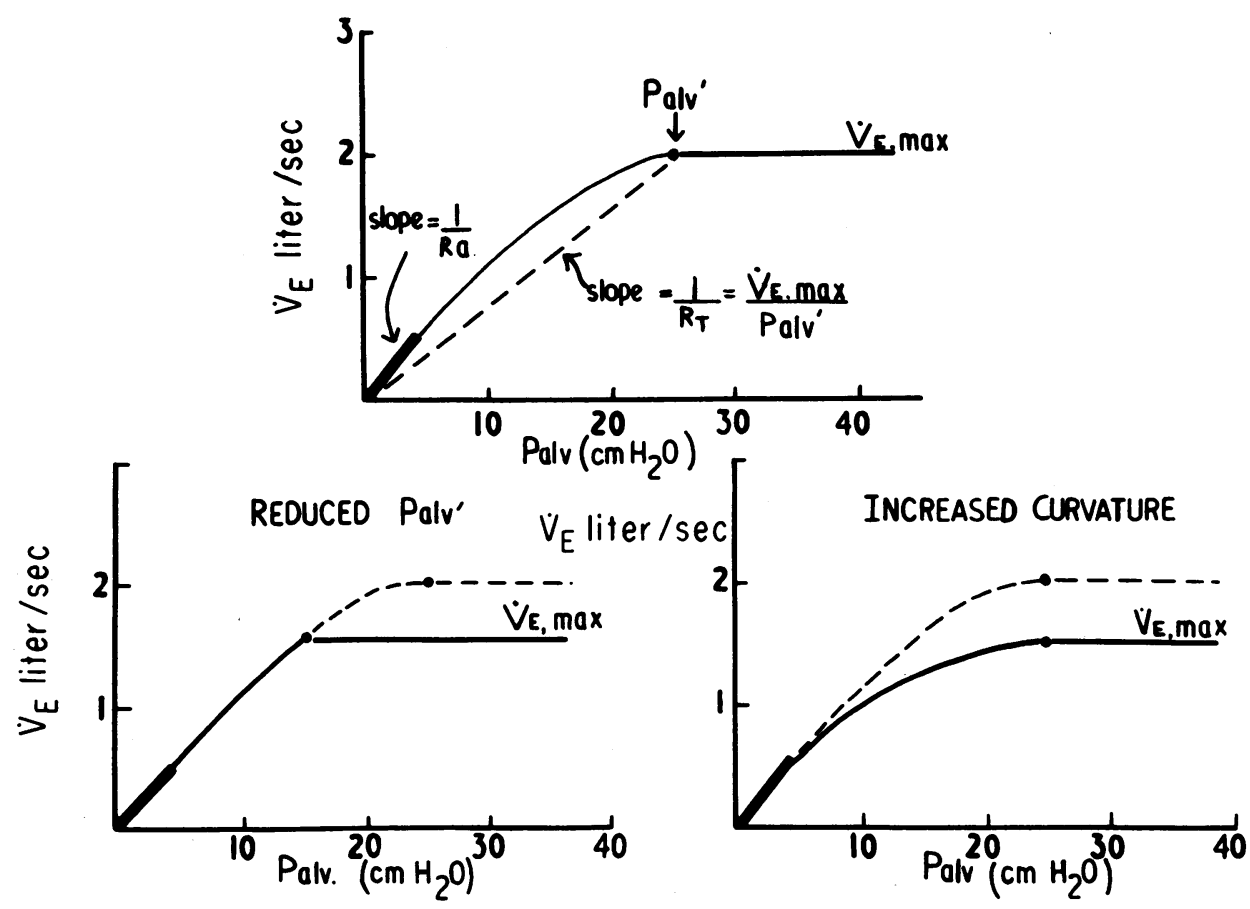

FIGURE 5 The relationship between airway resistance $(\mathrm{Ra})$, measured in a plethysmograph, and total pulmonary resistance $\left(R_{T}\right)$ computed from an IVPF curve. Maximum flow may be reduced without any change in the initial slope $(1 / \mathrm{Ra})$ if $\mathrm{P}_{\mathrm{alv}}{ }^{1}$ is reduced or if there is increased curvilinearity of the pressure-flow curve as flow increases.

is reduced (Fig. 6). After the administration of isoproterenol three changes were observed: $(a)$ The initial slopes were steeper, reflecting the expected increase in conductance at low flows; $(b)$ the plateaux of maximum flow were higher; and $(c)$ they were reached at lower alveolar pressures than formerly (Figs. 6 and 7 ). The last finding accounts for the increase in maximum flow being proportionately less than the increase in conductance at large lung volumes.

A reduction in $\mathrm{P}_{\mathrm{a} 1 \mathrm{v}}{ }^{1}$ will occur in three circumstances: (a) If there is a loss of lung elastic recoil pressure; or (b) if there is a disproportionate decrease in the resistance of the downstream segment (i.e. the largest intrathoractic airways and the extrathoracic airway) leading to a reduction in the ratio $\mathrm{Rd}$ : Rus (equation $5)$; or (c) if there is a change in collapsibility of the airways. Measurements of static pressure-volume curves showed that, after isoproterenol, lung elastic recoil pressure was significantly reduced at all lung volumes between 30 and $85 \%$ of the vital capacity (Fig. 8 and Table III). We were able to follow the time course of these changes in subjects D.D. and G.F. (Fig. 9). 5 min after inhaling isoproterenol, the curves were maximally displaced to the left (broken curves) and then they began to return toward the control state (dotted curves represent the $30 \mathrm{~min}$ value). By $60 \mathrm{~min}$, the effect was dissi- pated, and there was no appreciable difference between the data obtained at this time and the observations before isoproterenol (solid line). Because these studies were performed separately from the main body of investigations, there is a difference in the absolute values of the curves shown in Figs. 8 and 9. We believe that this is due to different balloon positions in the esophagus between the two experiments. However, since we are certain that there were no within experiment variations in position, and since we were only interested in the change from the control observations, we do not feel that this discrepancy invalidates our argument.

It is more difficult to make an accurate assessment of the changes in the $\mathrm{Rd}$ : Rus ratio following isoproterenol because of the critical dependence of $\mathrm{Rd}$ on the estimate made of $\mathrm{P}_{\mathrm{a} 1 \mathrm{v}}{ }^{1}$. However, our calculations show that, if anything, there was a slight increase in this ratio (Fig. 10) at larger lung volumes after isoproterenol. These observations led us to conclude that there was no selective action of isoproterenol and that the increase in airway dimensions occurred in all parts of the tracheobronchial tree.

By plotting the conductance of the upstream segment during a forced expiration (Gus) against lung volume, it is possible to assess the role that the change in elastic recoil plays in minimizing the increase in maximum 

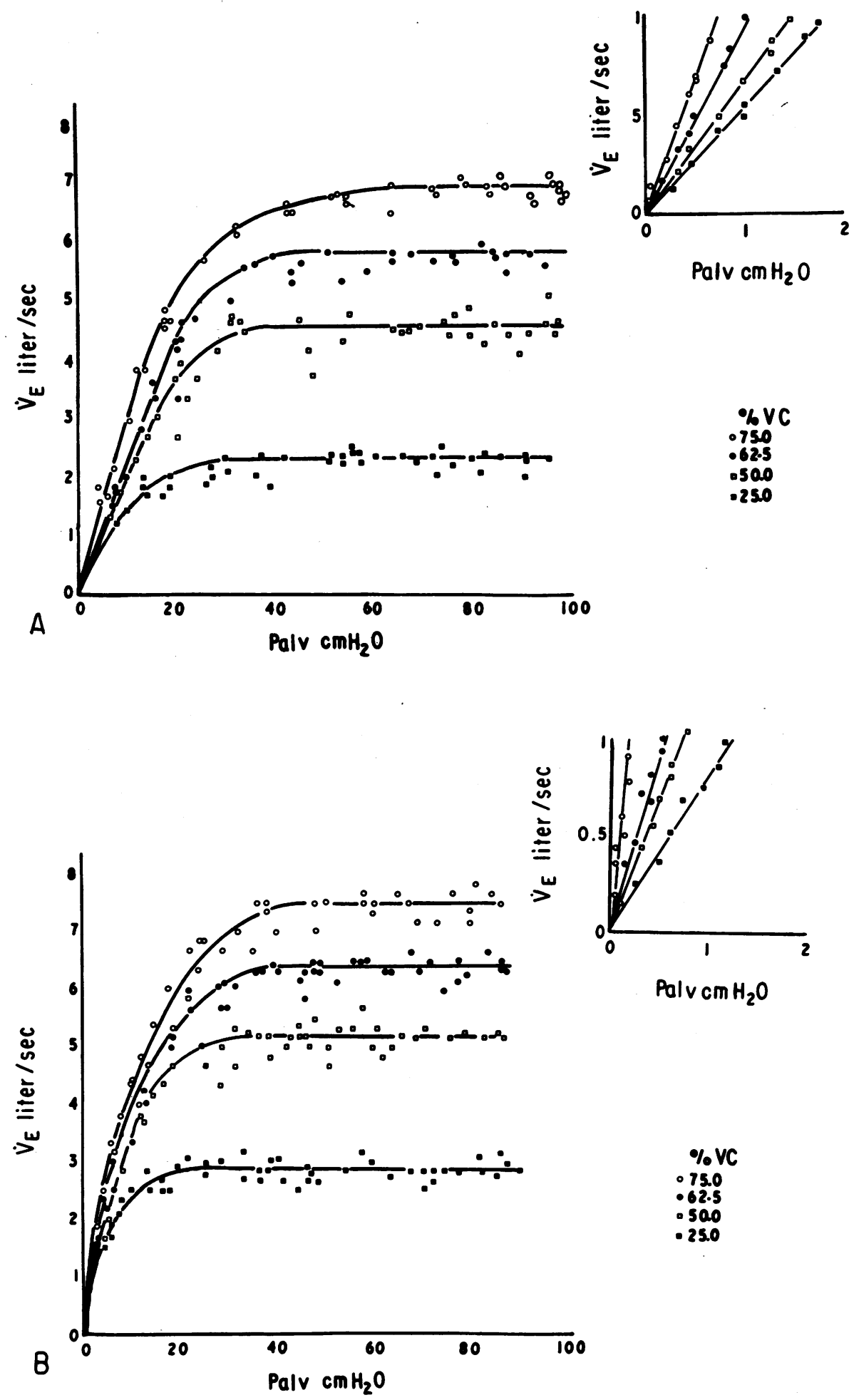

Palv $\mathrm{Cm} \mathrm{H}_{2} \mathrm{O}$

FIGURE $6 \mathrm{~A}$ Isovolume pressure-flow curves in subject D.D. before isoproterenol. B: IVPF curves after isoproterenol. The inserts indicate the initial portions of the IVPF relationships at low flow and pressure. 


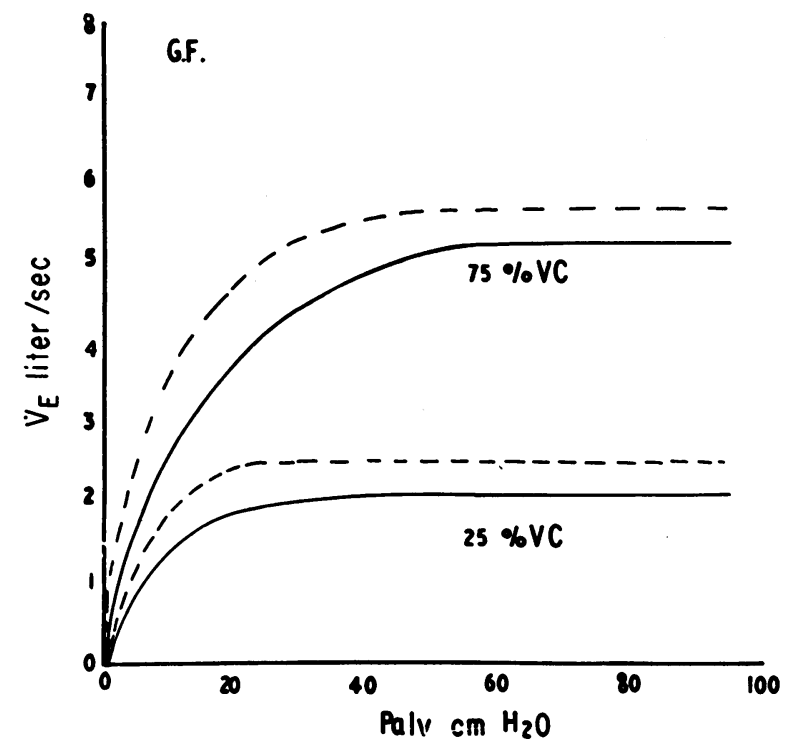

FIGURE 7 IVPF curves in subject GF, before (solid lines) and after (broken lines) isoproterenol.

expiratory flow after isoproterenol inhalation. Fig. 11 shows that there was a considerable improvement in Gus which was nearly as great at large as well as at small lung volumes. If there had been no change in the pressure-volume relationships of the lung, then maximum flow would have been expected to have increased at least in proportion to the change in Gus.

\section{DISCUSSION}

Previous studies $(2-4)$ have suggested that the inhalation of isoproterenol in normal subjects results in relatively large increases in airway dimensions, during quiet breathing, without much change in flow rates on maximum efforts. In general, the present results confirm this suggestion, although when the effect of lung volume is taken into account, it becomes apparent that this disparity is confined to the upper part of the vital capacity. At small lung volumes the increase in flow is, if anything, more pronounced than the change in conductance (Fig. 4).

We believe that the greatest part of this discrepancy can be accounted for by our finding that the elastic recoil pressure of the lung is temporarily reduced after isoproterenol. Two recent studies have emphasized the importance of static recoil pressure as a direct determinant of maximum expiratory flow $(15,16)$, and the changes we observed in the isovolume pressure flow curves are such as would be predicted for a reduction in elastic recoil pressures from these analyses. In addition, Machlem and Mead (17) have demonstrated that in normal lungs at high volumes the most important determinants of $\vec{V}_{\mathbf{E}_{\text {max }}}$ are the cross-sectional area at the equal pressure point and lung elastic recoil. In their analyses, any increase in airway size, such as that which occurred in the present study, would diminish the resistance to convective acceleration and thus cause
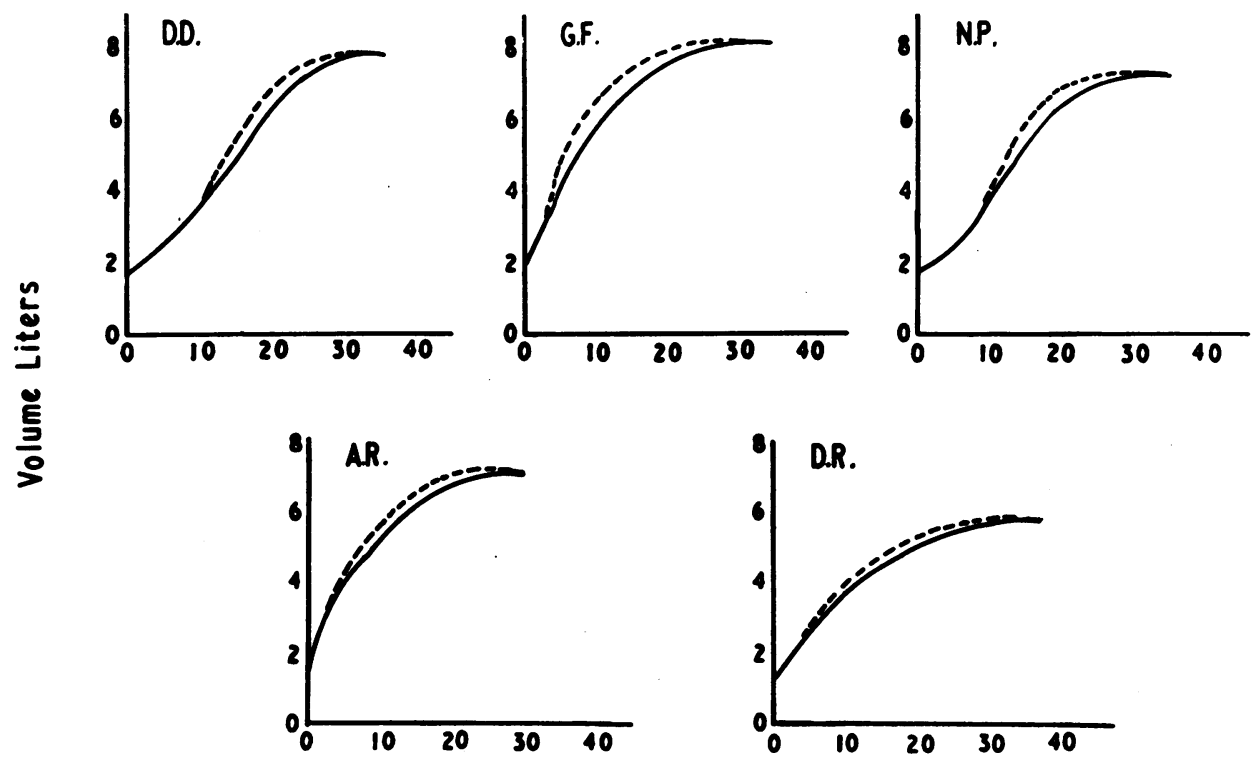

Pst $\mathrm{cmH}_{2} \mathrm{O}$

Figure 8 Static pressure-volume relationships of the lungs before (solid lines) and after (broken lines) isoproterenol. 

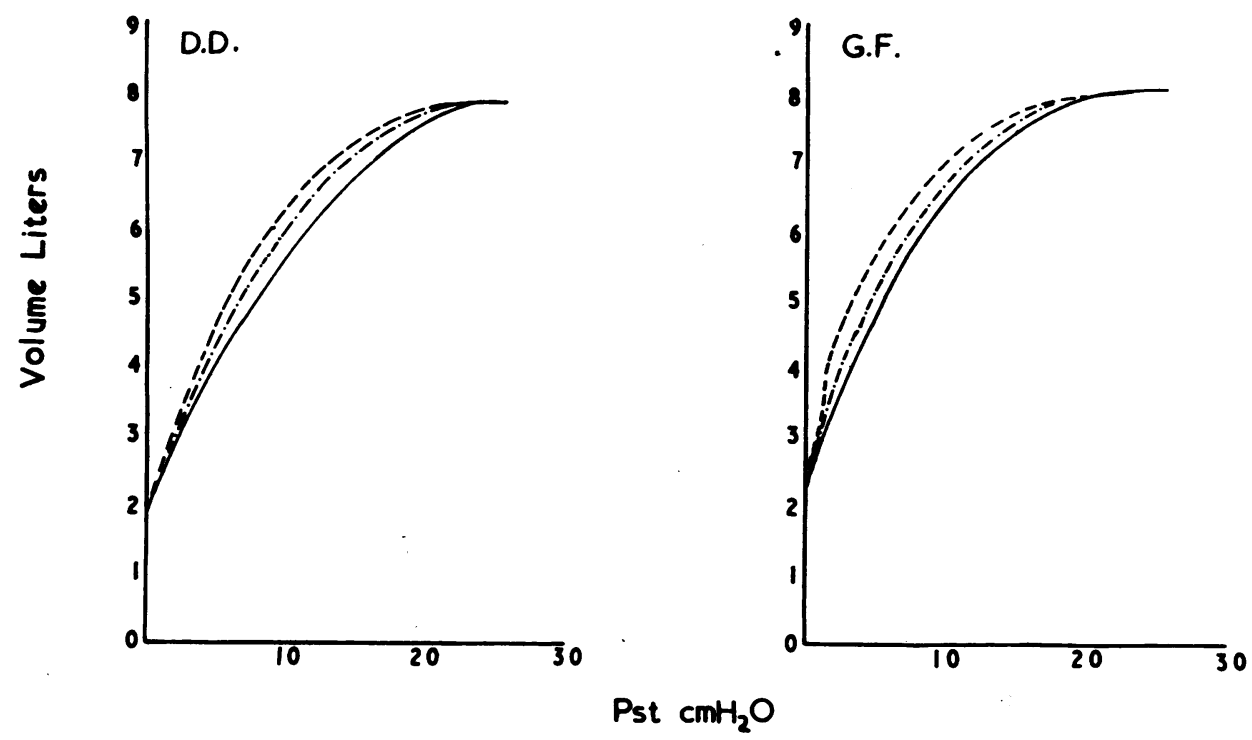

FIGURE 9 Static pressure-volume relationships of subjects D.D. and G.F. before (solid lines) and after (broken lines) isoproterenol. The broken curves are observations made at $5 \mathrm{~min}$. The dotted curves are those at $30 \mathrm{~min}$, while the solid curve presents both the control situation as well as $60 \mathrm{~min}$ postisoproterenol.

a proportionate elevation in airflow rates unless static recoil pressure fell.

It appears that the effect of isoproterenol on flow rates is only fully appreciated at low lung volumes where the normal recoil pressure combines with the dilated airways to produce the greatest increase in $\mathrm{V}_{\mathbb{B}_{\max }}$. This too is in keeping with published observations (17) that maximum flow at low lung volumes is determined mainly by lung recoil and the frictional resistance of airways upstream from the equal pressure point.
The changes that we describe can also be contributed to by two other factors: a change in the critical closing pressure of the flow-limiting segment and(or) selective bronchodilatation of large airways. The mechanism limiting flow on forced expiration in normal subjects is believed to be narrowing of large airways close to the carina (18). If the flow-limiting airways were rendered more susceptible to compressive forces, the flow plateau on the IVPF curve would develop at a lower alveolar pressure, but measurements of resistance made with the panting technique would not be affected to any great

TABLE III

Slatic Recoil Pressure at Various Lung Volumes before and after Isoproterenol

\begin{tabular}{|c|c|c|c|c|c|c|c|c|c|c|}
\hline \multirow[b]{3}{*}{ Subject } & \multicolumn{10}{|c|}{ Per cent vital capacity } \\
\hline & \multicolumn{2}{|c|}{$85 \%$} & \multicolumn{2}{|c|}{$75 \%$} & \multicolumn{2}{|c|}{$50 \%$} & \multicolumn{2}{|c|}{$25 \%$} & \multicolumn{2}{|c|}{$12.5 \%$} \\
\hline & B & $\mathbf{A}$ & B & $\mathbf{A}$ & B & $\mathbf{A}$ & B & A & B & A \\
\hline D. D. & 25.2 & 21.8 & 19.2 & 17.6 & 15.0 & 14.0 & 9.8 & 9.0 & 4.8 & 4.9 \\
\hline G. F. & 19.2 & 14.0 & 14.6 & 10.2 & 8.0 & 6.0 & 3.0 & 3.0 & 1.3 & 1.3 \\
\hline N.P. & 21.8 & 18.2 & 17.0 & 14.6 & 11.9 & 11.1 & 7.4 & 7.4 & 5.3 & 5.2 \\
\hline A. $\mathbf{R}$. & 16.8 & 14.4 & 11.0 & 9.4 & 6.0 & 5.0 & 2.3 & 2.0 & 1.0 & 1.0 \\
\hline D. R. & 29.0 & 23.0 & 21.4 & 18.2 & 13.4 & 11.0 & 6.6 & 5.4 & 3.0 & 3.0 \\
\hline Mean & 22.4 & 18.3 & 16.6 & 14.0 & 10.9 & 9.4 & 5.8 & 5.4 & 3.1 & 3.1 \\
\hline $\pm S D$ & 4.8 & 4.1 & 4.0 & 4.1 & 3.8 & 3.8 & 3.1 & 2.9 & 1.6 & 1.6 \\
\hline$P$ Value & \multicolumn{2}{|c|}{0.003} & \multicolumn{2}{|c|}{0.008} & \multicolumn{2}{|c|}{0.01} & \multicolumn{2}{|c|}{0.12} & \multicolumn{2}{|c|}{ - } \\
\hline
\end{tabular}

$\mathrm{B}=$ before isoproterenol ; $\mathrm{A}=$ after isoproterenol; values shown in body of table are expressed in $\mathrm{cm} \mathrm{H}_{2} \mathrm{O}$. 

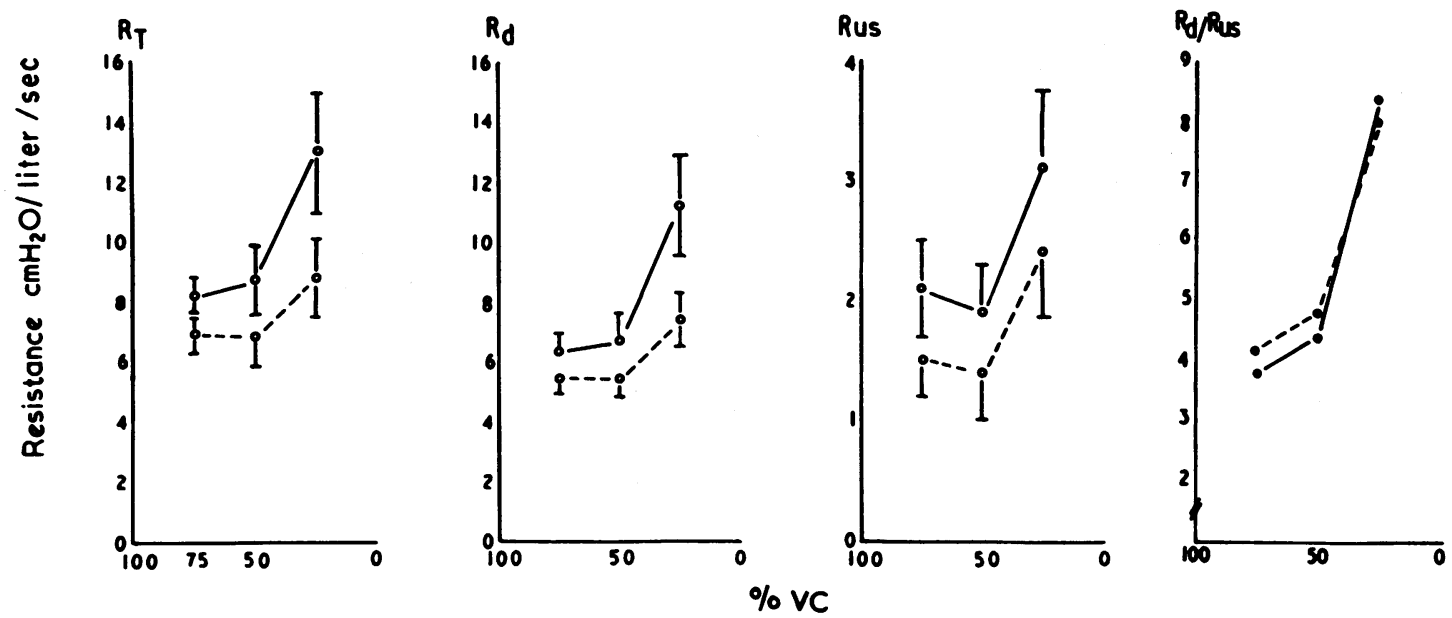

FIGURE 10 Partitioning of total pulmonary resistance $\left(R_{T}\right)$ into its downstream ( $\left.R d\right)$ and upstream (Rus) components at various lung volumes. Solid lines indicate control data, broken lines represent postisoproterenol observations. The data points are mean values, and the bars indicate the standard error. Changes in Rd: Rus ratio are also shown.

extent. This type of change (a reduced maximum expiratory flow at volumes where there is a normal resistance at a flow of 0.5 liter/sec) has recently been reported in asymptomatic asthmatics (19). The effect of a change in airways collapsibility cannot be specifically estimated by the use of the equal pressure point concept of Mead et al. (15). Using Mead's method of analysis, if isoproterenol only caused increased collapsibility of flow-limiting airways, this would yield an apparent increase in upstream resistance on forced expiration (see reference 16). If, however, the airways dilated as well as increased their compliance, both Rus and $\mathrm{Palv}^{1}$

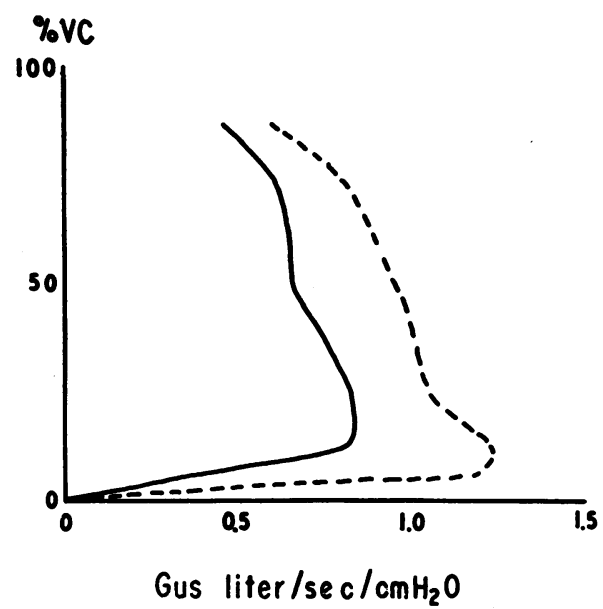

Figure 11 Mean conductance of the upstream segment for five subjects before (solid line) and after (broken line) isoproterenol. Data were obtained by plotting the ratio of maximum expiratory flow (obtained from MEFV curves) to the static recoil pressure of the lungs. could be reduced and increased curvilinearity would be seen on the IVPF curve. Thus an alteration in the elastic properties of the airways could well account for part of our observations.

It has been suggested that selective dilitation of the airways in the downstream segment of the tracheobronchial tree may not affect the level of flow on the plateau of an IVPF curve (16). The largest airways in the larynx account for a considerable proportion of the total airway resistance $(20)$, so that if bronchodilitation was confined to these areas, there could be a large decrease in resistance without an increase in maximum flow. Although our data demonstrate that the largest airways were, indeed, dilated, our estimates of $\mathrm{Rd}$ : Rus suggest that there was little change in the distribution of resistance between these segments. Therefore selective action of isoproterenol did not seem to occur.

We do not know the cause of the temporary loss of elastic recoil pressure after isoproterenol. There were no acute changes in total lung capacity. Balloon volume and position was repeatedly checked and did not vary. The rapid time course makes it unlikely that it could have been associated with any change in surfactant. The available evidence does not suggest that isoproterenol causes a large decrease in central blood volume (21). The most likely cause is that the change in overall lung pressure-volume characteristics was due to dilatation of the smallest muscular airways which contain a considerable proportion of the total lung volume. Nadel, Colebatch, and Olsen (22) have shown that microembolization can cause these airways to constrict with the result that the pressure-volume curve shifts to 
the right. These investigations also demonstrated that these changes can be prevented or partially reversed by isoproterenol. Although we know of no direct evidence that bronchodilatation promotes a shift in the pressure volume relationship of the lungs in normal man, indirect evidence can be obtained from several sources. Butler, Caro, Alcala, and DuBois (2) noted an increase in compliance in an asthmatic subject given Isuprel. Symptomatic patients with asthma usually decrease their static compliance when given bronchodilators $(19,23)$, while DuBois and Dautrebande (3) reported an increase in dynamic compliance in two subjects given aerosols of isoproterenol, cyclopentamine, and procaine in $80 \%$ propylene glycol.

If our contention is correct that the fall in static recoil pressure at high lung volumes is responsible for the small increase in $\mathrm{FEV}_{1}$ then serial measurements of the variable might show a greater percentage increase at a time when there is still bronchodilatation, but when the pressure-volume relationship is approaching normal. In subject G. F. the base line $\mathrm{FEV}_{1}$ was 4.93 liters, and it improved $6.2 \%$ to 5.24 liters 10 min after being given isoproterenol; at $30 \mathrm{~min}$ it increased an additional $4.3 \%$ to 5.47 liters. We offer this observation as supporting evidence that the early change in recoil pressure negates the enlargement in airway diameter.

The decrease in elastic recoil that we describe may be related to the dose of isoproterenol used ( $1 \%$ solution). Subsequent experimentation has suggested that if a $1: 200$ dilution ( $0.5 \%$ solution) or less is employed, the effects on the pressure-volume curve are inconsistent.

Both spirometry and airway resistance are commonly used to assess bronchial changes after drugs, air pollutants, or allergens. The present study indicates that if discrepancies occur between the size of the changes in the two types of tests, these should not be attributed indiscriminately to differences in "sensitivity" of the tests. These disparities may arise because of the inherent limitations within each technique. The present study emphasizes that measurements of maximum flows made at low lung volumes, such as the MMF or $V_{w_{\max }}$ at $50 \%$ of the vital capacity, tend to reflect primarily the behavior of the peripheral airways. These findings tend to confirm the observations of others (24-26). Airway resistance, on the other hand, predominantly measures the magnitude of the downstream resistance and tends not to detect small deviations in Rus (19).

Other factors to be considered are the possibility of a selective action of a drug on a particular part of the trachobronchial tree or because it also affects bronchial collapsibility or lung compliance. Although in the present instance the greater changes were in resistance, in other situations such as aging with its loss of lung elastic recoil, changes in maximum flow might well be greater than changes in resistance. Therefore, we feel that in studying the pulmonary response to a foreign substance the essential first step is to make a detailed study of the changes the substance produces in the pressure, flow, and volume interrelationships of the lungs. Only when these are known is it possible to select the most appropriate simple test for use on a wider scale.

\section{ACKNOWLEDGMENTS}

We gratefully acknowledge the cooperation of our colleagues Doctors D. Denison, G. Field, A. Raimondi, D. Robertson, D. McCarthy, S. Spiro, and G. Jones who served as our subjects in this investigation and the support of the Department of Medical Research and Development, William Beaumont General Hospital, in preparation of the manuscript.

\section{REFERENCES}

1. Dautrebande, L. 1952. Physiological and pharmacological characteristics of liquid aerosols. Physiol. Rev. 32 : 214.

2. Butler, J., C. G. Caro, R. Alcala, and A. B. DuBois. 1960. Physiological factors affecting airway resistance in normal subjects and in patients with obstructive respiratory disease. J. Clin. Invest. 39: 584.

3. DuBois, A. B., and L. Dautrebande. 1958. Acute effects of breathing inert dust particles and of carbachol aerosol on the mechanical characteristics of the lungs in man. Changes in response after inhaling sympathomimetic aerosols. J. Clin. Invest. 37 : 1746.

4. Dautrebande, L., F. Lovejoy, and H. Constantine. 1960. New studies on aerosols. XI. Comparative study of some methods used for determining constriction and dilatation of the airways after administering pharmacological or dust aerosols. Sensitivity of the plethysmographic method. Arch. Int. Pharmacodyn. Ther. 129: 469.

5. DuBois, A. B., S. Y. Botelho, G. N. Bedell, R. Marshall, and J. H. Comroe, Jr. 1956. A rapid plethysmographic method for measuring thoracic gas volume: a comparison with a nitrogen washout method for measuring functional residual capacity in normal subjects. J. Clin. Invest. 35: 322.

6. DuBois, A. B., S. Y. Botelho, and J. H. Comroe, Jr. 1956. A new method for measuring airway resistance in man using a body plethysmograph: values in normal subjects and in patients with respiratory disease. J. Clin. Invest. $35: 327$.

7. Fleisch, A. 1956. Le pneumotachographe. Helv. Physiol. Pharmacol. Acta. 14: 363.

8. Leuallen, E. C., and W. S. Fowler. 1955. Maximal midespiratory flow. Amer. Rev. Tuberc. 72: 783.

9. Mead, J., J. L. Whittenberger, and E. P. Radford, Jr. 1957. Surface tension as a factor in pulmonary volumepressure hysteresis J. Appl. Physiol. 10: 191.

10. Milic-Emili, J., J. Mead, J. M. Turner, and E. M. Glauser. 1964. Improved technique for estimating pleural pressure from esophageal balloons. J. Appl. Physiol. 19: 207.

11. Mead, J. 1960. Volume displacement body plethysmograph for respiratory measurements in human subjects. J. Appl. Physiol. 15 : 736.

12. Fry, D. L. 1958. Theoretical considerations of the bron- 
chial pressure-flow volume relationships with particular reference to the maximum expiratory flow volume curve. Phys. Med. Biol. $3: 174$.

13. Fry, D. L., R. V. Ebert, W. W. Stead, and C. C. Brown. 1954. The mechanics of pulmonary ventilation in normal subjects and in patients with emphysema. Amer. J. Med. $16: 80$.

14. Fry, D. L., and R. E. Hyatt. 1960. Pulmonary mechanics: a unified analysis of the relationship between pressure, volume and gasflow in the lungs of normal and diseased human subjects. Amer. J. Med. 29: 672 .

15. Mead, J., J. M. Turner, P. T. Macklem, and J. B. Little. 1967. Significance of the relationship between lung recoil and maximum expiratory flow. J. Appl. Physiol. 22: 95.

16. Pride, N. B., S. Permutt, R. L. Riley, and B. Bromberger-Barnea. 1967. Determinants of maximal expiratory flow from the lungs. J. Appl. Physiol. 23: 646 .

17. Macklem, P. T., and J. Mead. 1968. Factors determining maximum expiratory flow in dogs. J. Appl. Physiol. 25: 159.

18. Macklem, P. T., and N. J. Wilson. 1965. Measurement of intrabranchial pressure in man. J. Appl. Physiol. 20: 653.

19. McFadden, E. R., Jr., and H. A. Lyons. 1969. Serial studies of the factors influencing airway dynamics during recovery from acute attacks of asthma. J. Appl. Physiol. 27: 452 .

20. Ferris, B. G., Jr., J. Mead, and L. H. Opie. 1964. Partitioning of respiratory flow resistance in man. J. Appl. Physiol. 19: 653.

21. Gorten, R., J. C. Gunnells, A. M. Weissler, and E. A. Stead, Jr. 1961. Effects of atropine and isoproterenol on cardiac output, central venous pressure, and mean transit time of indicators placed at three different sites in the venous system. Circ. Res. 9: 979.

22. Nadel, J. A., H. J. H. Colebatch, and C. R. Olsen. 1964. Location and mechanism of airway constriction after barium sulfate microembolism. J. Appl. Physiol. 19: 387.

23. Gold, W. M., H. S. Kaufman, and J. A. Nadel. 1967. Elastic recoil of the lungs in chronic asthmatic patients before and after therapy. J. Appl. Physiol. 23: 433.

24. Leuallen, E. C., and W. S. Fowler. 1955. Maximal midexpiratory flow. Amer. Rev. Tuberc. Pulm. Dis. 72: 783.

25. Frank, N. R., M. O. Amdur, J. Worcester, and J. L. Whittenberger. 1962. Effects of acute controlled exposure to $\mathrm{SO}_{2}$ on respiratory mechanics in healthy male adults. J. Appl. Physiol. $17: 252$.

26. Bouhuys, A., V. R. Hunt, B. M. Kim, and A. Zapletal. 1969. Maximum expiratory flow rates in induced bronchoconstriction in man. J. Clin. Invest. 48: 1159. 